\title{
Language, food and gentrification: signs of socioeconomic mobility in two Gothenburg neighbourhoods
}

\author{
Johan Järlehed \\ University of Gothenburg, Department of Languages and \\ Literatures
}

\author{
Helle Lykke Nielsen \\ University of Southern Denmark, Centre for the Middle East \\ Studies \\ Tove Rosendal \\ University of Gothenburg, Department of Languages and \\ Literatures
}

Correspondence to: Johan.jarlehed@sprak.gu.se

\begin{abstract}
This paper examines at how language and food intersect and interact in gentrification processes. As a capital-driven social process aiming at enhancing the socioeconomic value of urban space, gentrification implies mobility both in the sense that it attracts new people, businesses and capital to an area, and in the form of displacement of less affluent and prestigious people, businesses and semiotic resources from central to marginal urban spaces. The paper examines linguistic and visual traces of such mobilities in two neighbourhoods in Gothenburg, Sweden. Based on the observation that food and food practices are central for the production and reproduction of social distinction, the analysis centres on food related establishments and signs. In particular, it discusses the distinction-making function of prestigious languages, elite gastronomic registers, and gourmet food trucks, and how these depend on the marginalization of low status languages, popular gastronomic registers and cheap generic food carts. People's interaction with these resources contributes to the reconfiguration of social and urban space.
\end{abstract}

Keywords: gentrification, distinction, gastronomic register, food trucks, linguistic landscape 


\section{INTRODUCTION}

Cities are in constant change as people and capital move in and out of particular neighbourhoods. Cities also feature social inequalities as economic wealth, cultural capital, and political power are unevenly distributed. The city of Gothenburg, Sweden, is no exception. In 2021, the city celebrates its 400th anniversary and for this occasion large parts of the city are being rebuilt and renovated. As part of the anniversary vision, the city council stresses the increased socio-cultural and linguistic diversity of the inhabitants resulting from immigration and underlines the importance of creating an open and inclusive ambience (City of Gothenburg 2018). The renovations and reconstructions imply changes that not only affect people who live and work in specific areas, but also create new patterns of mobility by attracting new visitors to these areas.

Gentrification emerges as a central process and concept for the study of socioeconomic mobility in urban spaces. Simply understood as the socioeconomic upscaling of a neighbourhood and its inhabitants, gentrification has been widely discussed within social sciences (see e.g. Shaw 2008; Zukin 2010), but less so within language studies (see Papen 2012; Lyons and RodríguezOrdóñez 2015; Trinch and Snajdr 2017 for exceptions). Being both driven by and contributing to the unequal distribution of power, capital, and space, gentrification is intimately linked to socio-economic mobility and segregation (Holgersson and Thörn 2014).

The linguistic landscape of a neighbourhood is embedded both in activities on the local scale, among its residents and visitors, and on a translocal scale through use of specific global, international languages and registers, but also through flows and (im)mobility of people, products, and capital (Lou 2016). Patterns of socioeconomic (im) mobility leave physical and linguistic traces in urban space, and such traces look different in economically advantaged and disadvantaged spaces, or in what Stroud and Mpendukana (2009) call 'sites of luxury' and 'sites of necessity'.

Food has always been a central ingredient of life, as both nourishment and culture. However, within present day urban landscapes and lifestyles, especially in gentrified areas, food has become even more important as a resource for the production of symbolic and economic value (Berg and Sevón 2014; Roe, Sarlöv Herlin, and Speak 2016). At the same time, patterns of social inequality are reflected in which cuisines, and associated 'languages' and 'cultures', are seen as trendy and prestigious, and which are not (Martin 2014).

In this paper, we want to tie these observations together as we analyse the semiotic landscape (Jaworski and Thurlow 2010) in two Gothenburg neighbourhoods. In particular, we examine how food and language-broadly understood - interact in the making of place, and how specific linguistic varieties and gastronomic registers displayed on food-related establishments function within gentrification and migration processes. Throughout the analysis we are concerned with inequality as materialized in practices of social differentiation and spatial segregation.

\section{GASTRONOMIC REGISTERS, (IM)MOBILITY AND SCALING IN URBAN SPACE}

The city has been described as 'a mosaic of polarised geographies of wealth, social 
status, health, ethnicity and gender', and language (Giolla Chríost 2007: 10). This means that we can expect noticeable differences between different areas of a city: language, money, space, and power are unevenly distributed. At the same time, cities are in constant movement and change, and people with different backgrounds and social positions are living, working and moving side by side. However, differences are often upheld despite mobility: people tend to stick to their own group and class, creating a sort of 'uneasy co-existence' (Shortell 2016: 80) or 'parallel play' (DeSena 2012: 82) of distinct groups. The (re)production of difference and distinction then emerges as a core activity of urban life. As will be illustrated by the analysis presented in this paper, this can be seen in the 'scalar practices' and 'scalar work' (Carr and Lempert 2016) involved in gentrification processes, whereby particular semiotic resources are used for (re)producing and challenging social imagination and differentiation tied to place. Such semiotic resources include, but are not limited to, national languages and indexes, i.e. words and expressions associated with specific languages and cultures. Furthermore, they include varied constellations of 'visual multilingualism' (Kelly-Holmes 2014) and forms linked to what we here call gastronomic registers, that is, 'ways of speaking' in relation to food products and practices (e.g. merchandising, consumption) that index socially imagined configurations of class, ethnicity and (im)mobility. As signalled by the quotation marks, we develop a multimodal and socio-semiotic understanding of register as comprising visuals, colour, (typo)graphic design in addition to verbal 'language'.
Gentrification is linked to migration and segregation in dynamic and complex ways. Many researchers have shown how gentrification processes contribute to spatial segregation within cities, since people with lesser resources are forced to move out of gentrified neighbourhoods. Shortell (2016: 223) argues that the more immigrant neighbourhoods are stigmatized, the easier it is for urban planners and developers $[\ldots]$ to frame gentrification as a solution to the problem' (see also Holgersson 2014). At the same time, and to a certain extent, different groups often co-exist in gentrified neighbourhoods since 'members of the ethnic/racial majority (higher in class and status) often regard the presence of other groups as a desirable characteristic, part of what makes the neighbourhood exotic or gritty, or even authentic' (Shortell 2016: 210). This is no surprise as long as the Others not are too many, or associated with low status groups, places, and languages (see our analysis of the differentiated use and value of Arabic in different parts of Gothenburg below).

As shown by Trinch and Snajdr (2017), a core feature of gentrification is distinction. Distinction then does not just mean that something is different from something else, but that this difference is socio-economically recognized and valued (Bourdieu 1984). Trinch and Snajdr (2017) identify two types of signs which are vital when analysing economic and social aspects of ongoing gentrification processes: 'Old School Vernacular' and 'Distinctionmaking signage'. 'Old school' signs index capitalism without distinction, by including all languages used by people living in the neighbourhood, thus bringing inclusivity in the neighbourhood economy. Contrary to this, distinctionmaking signage represents 'an exclusivity 
that for some readers also represents exclusion' (ibid.: 64). These signs are often minimalistic (for example, they use one word or a short phrase in reduced font size, often with lower case letters) and frequently display playful metareferences, polysemic or cryptic names, or use languages that index sophistication and worldliness (ibid.: 75). In distinction-making signs the use of languages is symbolic or fetishised rather than instrumental-communicative (Kelly-Holmes 2014). Thus, the content is not always understood by the audience. The English or other prestige languages used for this kind of signage in gentrified and socio-economically stratified neighbourhoods contribute to scaling up the value of the neighbourhood, its people, and businesses. In such areas, outside the Anglophone world, English has an emblematic function, along with other prestigious languages, as opposed to a referential use of other languages (Vandenbroucke 2016).

In their analysis of linguistic and cultural commodification processes in Chinatown, Washington DC, Leeman and Modan (2009: 332) argue that we need to examine 'how written language interacts with other features of the built environment to construct commodified urban places'. In this paper, we are not just studying commercial signage, but also the impact of religious institutions on the linguistic landscape (see Blommaert 2013). In doing so, we see how written and visual language interacts with the built and social environment; here, the religious institutions condition signage and physically attract people to the area. The rhythm of a place is composed by people's daily movements, and simultaneously the 'institutional arrangements and the material affordances' that condition them (Edensor 2010: 70). This means that when we are examining the rhythm of a particular place we must take into account human, linguistic, institutional, and built features. Mobility within a city is dynamic and varies from place to place and with time.

In line with critical sociolinguistics' and discourse analysis' intents to reveal and counter social inequality, we approach the notion of language as 'a set of resources which circulate in unequal ways in social networks and discursive spaces' (Heller 2007: 2). That is, 'language' should not be seen as one sole homogeneous thing (a system, structure, practice, etc.) but a complex and stratified set of communicative resources and 'features' (Jørgensen 2008). Since the usage of such resources and features is conditioned by social, economic, cultural, and political aspects, the im/ mobility of particular resources depends on 'the indexical value that [they] have in certain spaces and situations' (Blommaert 2010: 12). This means that we need to take the situated negotiation of indexicality into account in our analysis. We do this by focusing on the scalar work involved in the socioeconomic upscaling of place. Every time we move or imagine and present something as something else (bigger/smaller, better/worse, richer/ poorer, etc.) we engage in scalar work (Carr and Lempert 2016). However, it is important to distinguish between scale and value; a new perspective on something does not automatically imply or cause an up- or down-scaling of the value of the same thing. The economic value of language emerges when language 'can be exchanged for other symbolic or material resources' (Del Percio, Flubacher, Duchêne 2017: 55). Such exchanges often involve shifts of perspective and hence scalar work.

We engage in scalar work by choosing a prestigious 'language' for 
a restaurant name or a food product (within the contemporary Western world, these have typically included French and Italian), but also by deploying particular linguistic registers. Registers are 'forms of linguistic differentiation' (Irvine 2001: 33). They serve to position the speakers and interaction in social space, to align with or distantiate from certain social positions defined along continua of categories such as class, gender, and ethnicity. Put simply, 'the way people speak expresses and brings into being social differences' (Blackledge, Creese and Takhi 2014, 488). As part of 'a sociolinguistic economy' (Irvine 2001) or 'political economy of language' (del Percio, Flubacher and Duchêne 2017), particular registers, and other language features such as styles, 'are highly valued and rewarded while others get stigmatized or ignored', and 'expertise and access to influential and prestigious [registers], styles, genres, and media is unevenly distributed across any population' (Irvine 2001: 33). This way 'language and discourse play a central role in the production and legitimation of inequality and stratification' (Blommaert and Rampton 2011: 13). Furthermore, as forms of linguistic differentiation, registers always exist within 'a system of distinction'; they 'index properties of your present situation and social activity' or 'a situation you are trying to create' (Irvine 2001: 27). This means registers associated with high value and prestige are likely to be used - with more or less detail and proficiency - in aspirational interactions such as advertising or ordering of foodstuffs, where the speaker/writer either invites others or aims at being recognized as a member of some kind of elite.

Within increasingly multilingual urban centers, people meet a multitude of languages through their daily consumption. Even though most languages are likely to stay foreign and opaque to most people, particular expressions and words emerge as more or less emblematic indexes of entire languages and cultures. Within a political economy where cosmopolitanism and safe exoticism have high currency, market-smart people tend to pick up such foreign and exotic words and strategically use them for social positioning, i.e. for scaling up the social status of themselves, their taste, and their experiences. Many of these linguistic bits and pieces pertain to food products and practices. Tracing changes in the consumption of a particular foodstuff within one culture or country can reveal changes in taste regimes (Järlehed and Moriarty, 2018). An examination of the changing practices and infrastructure of a local food scene - i.e. what foodstuffs are offered where, how, and to whom - can tell us about similar changes in taste regimes and how they tie into local urban transformations related to gentrification. Furthermore, when one kind of food-based activity moves into a neighbourhood, another is often forced to move out (Martin, 2014). This is due to a combination of higher rents, city policies, and market-driven changes in consumer taste and demand.

In this paper we put forward the notion of gastronomic register to address the linguistic and semiotic practice of social differentiation and positioning as related to food and food practices. Gastronomic registers are thus seen as semiotic resources that serve to present and position speakers, practices and spaces/places in relation to food. Since registers as $\mathrm{Gal}(2018,3)$ says, are made up of "co-occurring forms [which] are usually not only linguistic but multimodal', they materialize in various ways. For instance, in the name of a particular food product 
in a specific language, in the usage of isolated language-specific expressions in a verbal exchange around food, in the visual display of particular food stuffs, or in the specific shape and look of a food truck. These register forms resonate distinction-making and scalar work related to food and social practices around food such as production, consumption and display. Consequently, gastronomic registers are an important part of what we elsewhere have called the semiofoodscape, that is, 'a dynamic social construction that relates food to places, people (class hierarchies) and materialities' (Järlehed and Moriarty under review: 2018:6).

\section{THE NEIGHBOURHOODS}

We have chosen to focus this study on two centrally located neighbourhoods in Gothenburg: Olivedal and Gamlestaden (see figure 1). The areas are comparable in size and structure, with a mix of residential buildings, businesses, and restaurants. However, socioeconomic and demographic data show that the inhabitants of the Olivedal neighbourhood are more affluent and well-educated than inhabitants in Gamlestaden, where we find more immigrants, with an income level below the city average (see table 1).

In this study we have chosen to document the northern part of the Olivedal area, close to the industrial harbour, more specifically the so-called

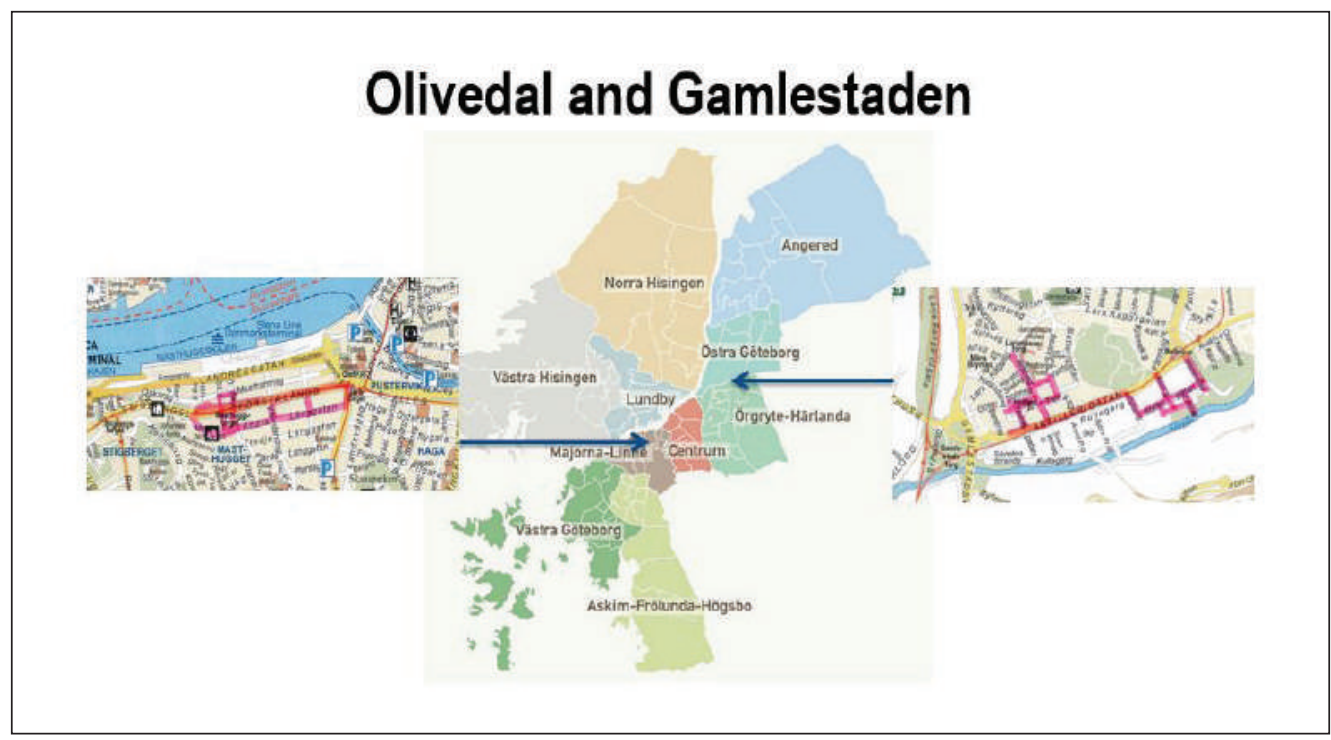

Figure 1: Gothenburg City Layout with Olivedal (left) and Gamlestaden (right). The red lines indicate the streets documented in our study.

Sources: Boplats (Areas in Gothenburg: https://nya.boplats.se/tipshjalp/sokahyresratt/kartor) and Official Tourist Map of Gothenburg and the Archipelago 2017/2018. 
Table 1: Olivedal and Gamlestaden: Socio-economic and demographic data

\begin{tabular}{llll}
\hline & OLIVEDAL & GAMLESTADEN & GOTHENBURG \\
\hline Population & 11,313 & 8,698 & 541,145 \\
Population changes 2013-2014 & +94 & +696 & $+7,874$ \\
Born abroad & $14.1 \%$ & $30.3 \%$ & $24.0 \%$ \\
Unemployment & $3.1 \%$ & $7.0 \%$ & $6.6 \%$ \\
College/university education (more than 3 years) & $50.6 \%$ & $31.2 \%$ & $33.9 \%$ \\
Participation in municipal election 2014 & $85.6 \%$ & $73.6 \%$ & $79.2 \%$ \\
\hline
\end{tabular}

Source: City Council of Gothenburg (Göteborgsbladet 2015 - Områdesfakta, Samhällsanalys och Statistik, Göteborgs stadsledningskontor)

Långgatorna (Första and Andra Långgatan, literally 'First Long street 'and 'Second Long street') and the streets found in between these long, parallel streets. The neighbourhood is situated west of the square Järntorget, which has been the centre for the labour movement since the late 1800 s and today is a vital traffic junction and meeting place. Today, the streets are characterized by restaurants, pubs, and small and independent shops, located in the typical three storey houses of the area. This part of town was originally built in the $\mathrm{mid} / \mathrm{end}$ of the 17 th century and had for a long time a rather bad reputation (the majority of the present buildings date from the 1870s-1910s, Hultgren 2012: 5). This old workers' neighbourhood is today gentrified and has transformed into a living area for high income citizens. However, the gentrification process is not totally completed. There are still some small, simple and cheap beer houses, alternative clothing shops, record shops, and vegan restaurants, as well as political organisations, which have resisted the ongoing transformation of the area. The area, especially the streets Langgatorna, is characterized by a special rhythm with buzzling restaurants and crowded pubs during weekend nights, but empty streets on a Tuesday at $10.30 \mathrm{am}$.

Built on a very old trading settlement, the other neighbourhood, Gamlestaden, is actually the oldest part of Gothenburg (Jörnmark, Forsemalm, and Palmås 2016). Today, we do not see any traces of the early settlements. The current buildings date from 1915 to 1960, with a mix of the typical one brick and two wooden storeys landshövdingehus (roughly 'Governor's house', a building type unique to Gothenburg), small squares, and curved streets. Most of the buildings were constructed at the beginning of the 20th century to accommodate workers and big, low-income families.

Gamlestaden earlier had the character of an industrial community at the outskirts of the city. Most people living here were employed by two big industries, the textile factory Gamlestadens Fabriker and the bearings and seal factory SKF (originally Svenska Kullagerfabriken), which is still a landmark of the area. Resulting from the socioeconomic upscaling of the area, families moved out to new-built, modern flats in the suburbs from the end of the 1950s onwards. The 
population of Gamlestaden decreased and the area became rather run-down. Today most houses are modernized or refurbished.

Today Gamlestaden has an air of a small town or a residential borough with minor businesses, shops, and cafés/ restaurants. The area is heavily influenced by car traffic, with a main big autostrada, Artillerigatan, cutting through the area, because of earlier plans to tear down the area. On the southern side we find the area called Bellevue with small-scale commercial activities, many ethnic shops, mosques, and religious associations. This part of the neighbourhood has become what Loukaitou-Sideris (2002) terms 'ethnically gentrified', that is a gradual displacement of traditional Swedish shops and business with commercial activities owned or run by mainly Muslim immigrants. North of the dividing street, we find restaurants, shops, official cultural institutions, schools, and residential areas. Gamlestaden is thus divided both physically and socially. We chose to include both these parts as this division of public space in Gamlestaden influences patterns of language use and mobility in the area. The mosques have a pull effect on visitors on Fridays in the Bellevue part, while cultural institutions have a similar pull effect through concerts etc. on the northern side of Artillerigatan.

\section{METHODOLOGY AND DATA}

We documented 9 streets, totalling 3460 meters, in Olivedal and 12 streets, totalling 3760 meters, in Gamlestaden. Four of the streets in the neighbourhood Gamlestaden were situated in the Bellevue quarter (1440 meters). Both the left and the right side of all streets were documented. A total of 226 storefronts in Olivedal and 157 in Gamlestaden were photographed in May 2016 (in addition to these, complementary overview-photos of streets were taken, as well as individual photos of parts of the storefronts and less permanent signage, such as stickers and posters). The individual photos were subsequently allocated to shop or activity storefront in NVivo 11, which we used as a database and analytical tool.

We employed a mixed methods approach, involving both quantitative and qualitative methods for the analysis. Each storefront was coded for number of languages $(1,2,3,3+)$, language choice and combination (e.g. Swedish and English; Swedish, Arabic and Kurdish) and hierarchy (first, second and third language). In addition we classified the type of activity of each unit of analysis (e.g. supermarket, hair salon, cultural association, religious institutions). Based on this coding we calculated the quantitative distribution and visibility of particular linguistic codes, combinations, and their visual hierarchy within each area.

We further made a thematic coding of all the photos, searching for and exploring patterns of sociolinguistic change (Coupland 2016). In addition to noting gastronomic registers (popular and elite registers), we thematically coded place (landmarks, linguistic place-marking, visual place- and culturemarkers), and signs of gentrification (minimalistic display, semiotic and linguistic play, 'time-markers' on signs). Even markers of historical migration, versatile business types visible on storefronts, transliteration practices, and visual multilingualism were identified.

Our data present a higher density of stores/businesses in Olivedal than in Gamlestaden. Additional detailed analysis of the amount, kind and content of the signs in the two neighbourhoods 
shows that Gamlestaden, with Hutton's words, is a more 'text-rich' area while Olivedal is more 'text-poor' (2011: 166), that is, signage in the former area is generally more loaded with written and visual symbols than signage in the latter area. Later, we will discuss these features some more with reference to Trinch and Snajdr's (2017) notions of 'old school' and 'distinction-making' signs.

\section{ENGLISH AS DISTINCTION- MAKING RESOURCE}

In the following sections, the use of language and 'languages' as part of gentrification processes and socioeconomic upscaling of neighbourhoods will be demonstrated and commented upon, starting with the use of English in Olivedal and Gamlestaden. The use of specific distinction-making languages illustrates value attribution to businesses, people and places, as shown here by the commodified use of English.

English is more frequent on signs in Olivedal than in Gamlestaden, both alone and in combination with Swedish. Almost $10 \%$ of the investigated Olivedal signs were written in English only, while English-only signs barely exist in Gamlestaden (only found on one storefront). We see the same pattern with the combination of Swedish and English. More than $40 \%$ of the signs in the Olivedal area were written in both Swedish and English, which is twice as frequent as in Gamlestaden. We also find a few combinations of English and another language in Olivedal. All these combinations are with other European languages. In Gamlestaden we only see one instance of the combination of English with another language: an English-Turkish storefront.
Piller (2001), in her study of advertising in Germany found that bilingual advertisements in English and German were used to reach middle-class Germans. These bilingual advertisements are attributed values such as internationalism, future orientation, success and elitism, sophistication, and fun (Piller 2001: 173). In the same way as bilingual use of German and English is "the "natural" option for successful middle-class Germans' (Piller 2001: 155), bilingual signs in Swedish and English, which frequently occur in Olivedal, emerge as the highest form of linguistic currency when targeting customers in this neighbourhood. This language combination thus serves for making Olivedal distinctive (Trinch and Snajdr 2017), that is, to attract capital in terms of both daily consumption and long term investments (e.g. housing and business). As shown in a number of studies (among others Thurlow and Jaworski 2003; Lin Pan 2010; Lanza and Woldemariam 2014), the English language serves as such a marker and producer of distinction around the world and is used for scalar work in both neighbourhoods.

Figure 2 shows a typical distinctionmaking sign in the trendy Olivedal neighbourhood. By choosing a prestigious name 'street life', written in English and with lower case letters, the producers index and try to create a cool, urban social activity and atmosphere.

'street life' is the name of a bar. However, the type of business is only indicated by the small Heineken name and symbol (red star) at the lower right bottom of the sign. The use of English here is clearly connotational (Piller 2001: 163) and emblematic (Vandenbroucke 2016: 97). English here indexes worldliness and sophistication and the bar-name has a youthful, hip 


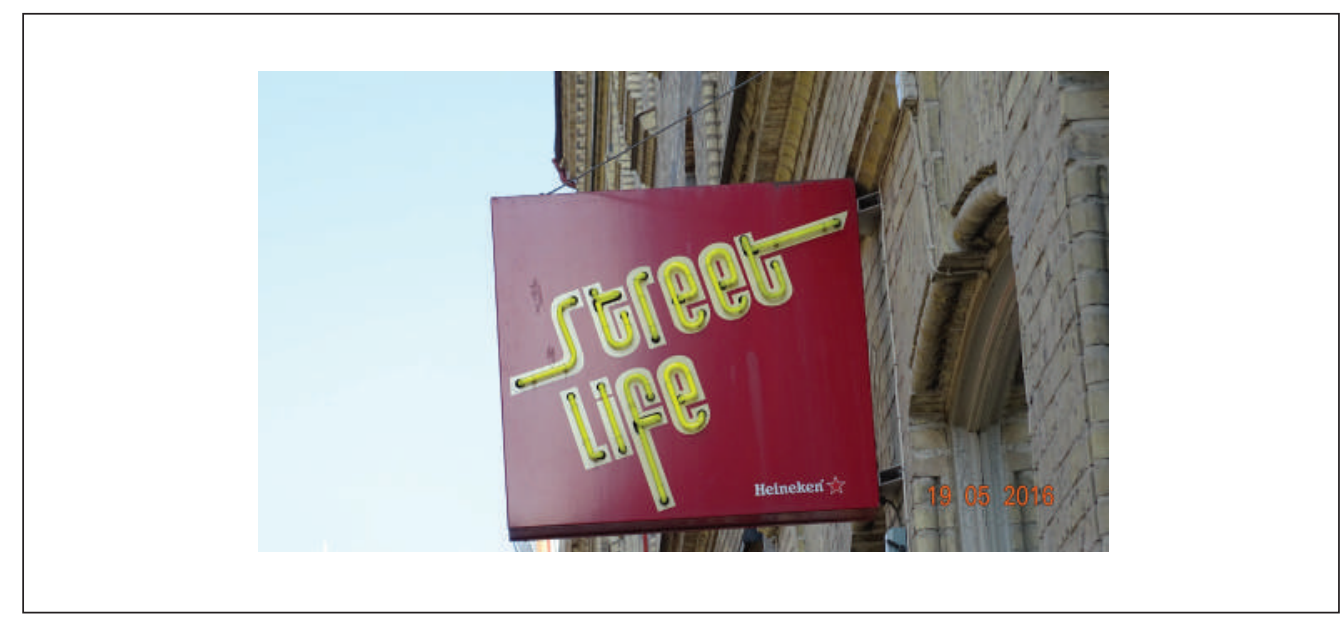

Figure 2: Distinction-making sign on Andra Långgatan, Olivedal ${ }^{1}$

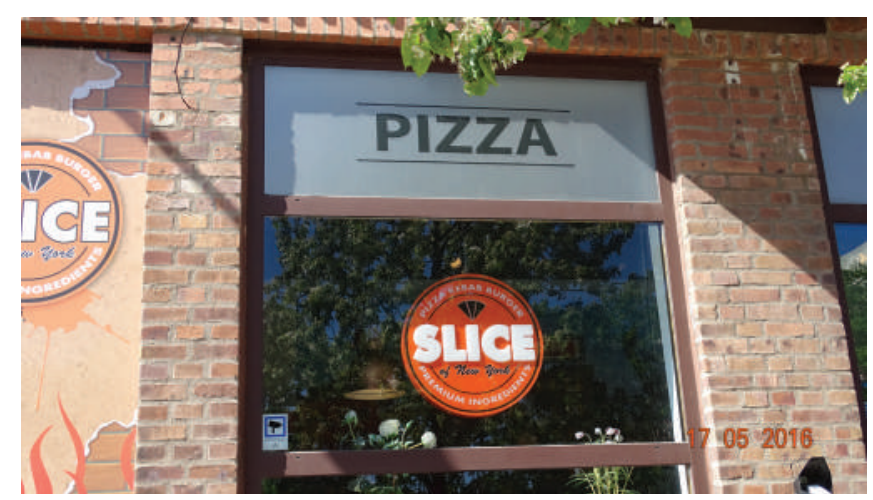

Figure 3: Distinction-making sign on Artillerigatan, Gamlestaden

urban connotation. The colourful neon design stresses the coolness. The sign is minimalist in not explicitly stating that it is a bar. This understatement is part of the up-scale sign design, which stresses distinction (Jaworski Forthcoming 2018). Thus, the sign serves to position and distantiate the business and uses English as part of the design.
Although infrequent, we find similar distinction-making signs in Gamlestaden. The local pizza restaurant 'SLICE of New York' in Artillerigatan is an example of such an up-scaling use of English, even in this neighbourhood.

The pizza snack bar has an orange circular neon sign with the name SLICE written in capital letters in white on

1 All the photos in the paper are taken by the authors.

(C) Järlehed, Lykke Nielsen, Rosendal and CMDR. 2018 
the orange background with 'of New York' printed in handwriting font below. PIZZA KEBAB BURGER is written above the name in the circular logo and PREMIUM INGREDIENTS under the logo. This trademark is also found on the windows of the place. On the windows of the snack bar either 'PIZZA', 'KEBAB' or 'BURGER' is written in big capital letters in black on a grey bottom on top of the window, accompanied by the logo/ trademark in orange centred below, in the middle of the window. This is clearly an aspirational use of English, aiming to associate the restaurant to worldliness and international, cosmopolitan New York. Simultaneously, what is offered (pizza, kebab, and hamburgers) is today regarded as typical Swedish fast food. The terms have entered a Swedish vocabulary available to the general public and are part of a Swedish gastronomic register which, instead of indexing urban elite, targets the ordinary men and woman in the street. This indicates that the use of English in signage is not per se a sign of upscaling processes. Furthermore, other languages mark social positioning related to food and food practices.
This use of valued languages as part of upscaling and as a visual sign of ongoing gentrification of the area are found in some establishments. Trattoria Maglia, for example, established in 2015 (written in Italian on the restaurant window: 'Dal $2015^{\prime}$ ) is situated in a piazza-like square in the centre of Gamlestaden, and is a White guide sister restaurant of a wellknown Italian restaurant in another part of Gothenburg, Majorna. The restaurant uses Italian as a distinction-making register, and serves 'Aperitivo' instead of 'After work', which is the coined Swedish/ Scandinavian term for meeting colleagues for a (happy hour) drink after work. The design stands out as typically discrete, with white letters on a black background, giving a sophisticated appearance; see Jaworski (forthcoming 2018).

Still, the more typical restaurants in Gamlestaden are run by immigrants from the Middle East/the Arabic-speaking world, the Balkans, and the Horn of Africa. Signs are information loaded and text dense, showing business, products, or services, which is typical for what Trinch and Snajdr (2017) call 'old school' signage. Often the store names, which are in large typefaces, refer to locations or

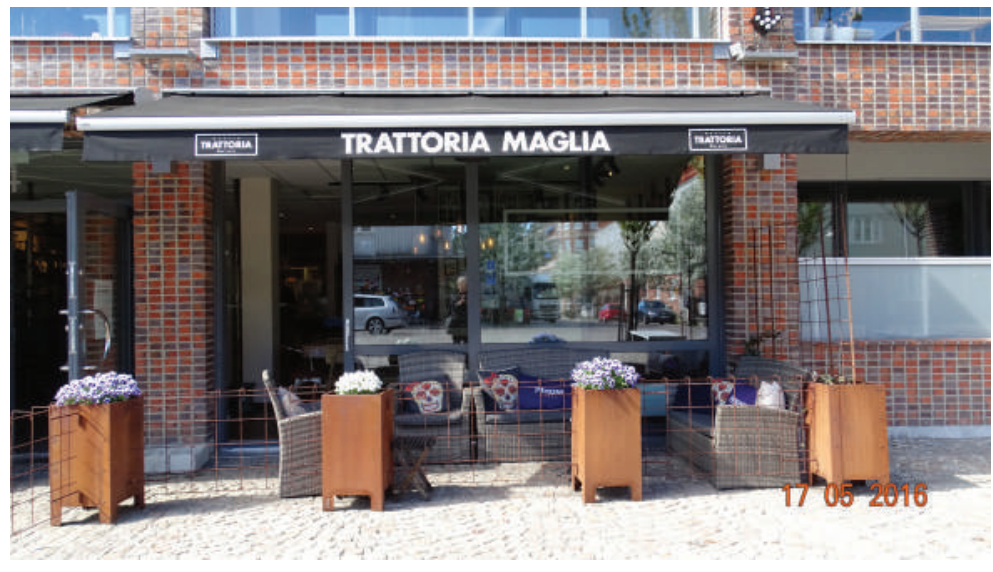

Figure 4: Signs of gentrification in Gamlestaden (Holländareplatsen 4-6) 
surnames, with additional symbols and pictures.

The combination of English and Swedish, which is often found in Olivedal (see above), is less frequent in Gamlestaden. When this combination is found, English has the same emblematic or symbolic function as found in the Olivedal neighbourhood (see the Gothia Falafel sign, figure 5).

Gothia Falafel is a Palestinian vegetarian/vegan fast food stand in Gamlestaden. Gothia Falafel is located in the premises of another restaurant, 'Old Corner', but is a separate business. The sign displayed in white on green uses a combination of English and Swedish. The trademark 'Gothia Falafel' is found above and under the actual locking window of the fast food establishment. 'Gothia' is an established international term, indexing contemporary Gothenburg and its relationship to the history of the Goths, frequently used in Gothenburg for hotels and sport events. Falafel is an established Swedish term today, thus does not form part of a prestigious register associated with a differentiated food practice. The sign also has the English name 'Old Corner' and the Swedish term LUCKAN 'locking window' in capital letters on the canopy above the locking window. In addition, a smaller neon sign in the window says 'Open' in English. This is a referential use of English. The same kind of pragmatic use of English, with 'WELCOME' in capital letters written on one window pane, is found in another small restaurant or snack bar in the area, serving Balkan specialties. This establishment additionally well illustrates businesses in Gamlestaden, with its 'old school', text-dense storefront, with nonstandard forms and complementary pictures. Even though the bar does not display any business name on the storefront, dishes on offer are written on a blackboard outside the restaurant, and a board in the window displays photos of dishes accompanied by the printed names of the dishes (Burek/Pita, Cevapi, Souvlaki). Inside the restaurant, Swedish and Bosnian are used on menus and other texts (sayings). It is clear that these sign producers use a specific gastronomic register to promote their businesses and simultaneously to socially differentiate and position them as serving authentic food.

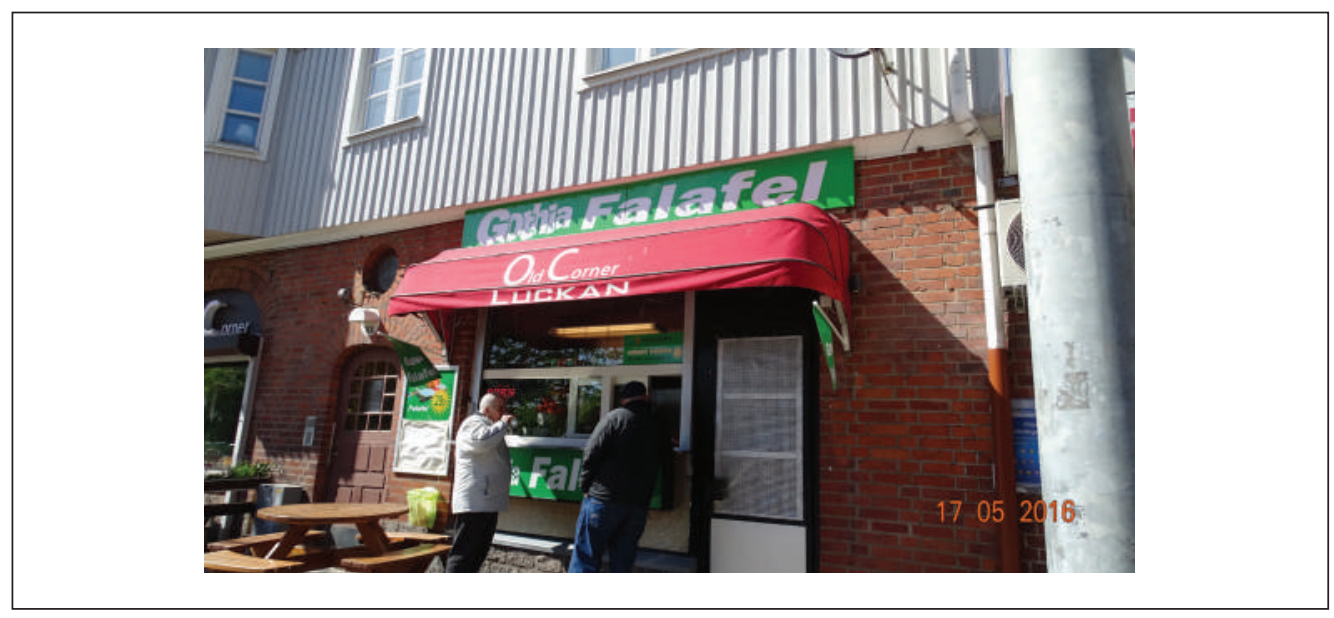

Figure 5: Emblematic usage of English in Gamlestaden (Artillerigatan) 
Neither Swedish nor Bosnian are associated with prestige in Gamlestaden. Additionally, Swedish functions as lingua franca for speakers of different immigrant languages, and is used referentially in combination with these languages in restaurant signs. The referential use of English is more frequent on other types of businesses in Gamlestaden, such as small travel businesses, money exchange, and money transfer agencies, in addition to small scale commerce, which often are much diversified shops.

\section{COMMUNICATIVE FUNCTIONS AND COMMODIFICATION OF}

\section{ARABIC}

Arabic is the most commonly used foreign language after English in the two neighbourhoods, though it is used to a significantly lesser extent in Olivedal than in Gamlestaden: a total of 24 storefronts used Arabic alone or in combination with other languages compared to 212 storefronts with English. Unlike English, which is generally considered a valued linguistic capital and used much more frequently in Olivedal than in Gamlestaden, Arabic is not associated with much prestige in Sweden or in Gothenburg due to its reputation as low status immigrant language. This is reflected in our data: Arabic occurs much more frequently in Gamlestaden, where more inhabitants are born abroad, unemployment rates are considerably higher and average income is considerably lower than in Olivedal (fig. 1): 22 storefronts in Gamlestaden used Arabic, mostly in combination with other languages, while only two - a Lebanese and a Palestinian restaurant - did so in Olivedal. The way Arabic is used on signs in the two neighbourhoods largely follows the pattern of pre- and post-gentrification signage described by Trinch and Snajdr for Brooklyn (Trinch and Snajdr 2017: 85-86), as will be illustrated in the examples below. Distinction-making signs dominate in the gentrified area of Olivedal and 'old school' vernacular signage in Gamlestaden. However, our data also shows that Arabic is used as a tool to upscale restaurants in both

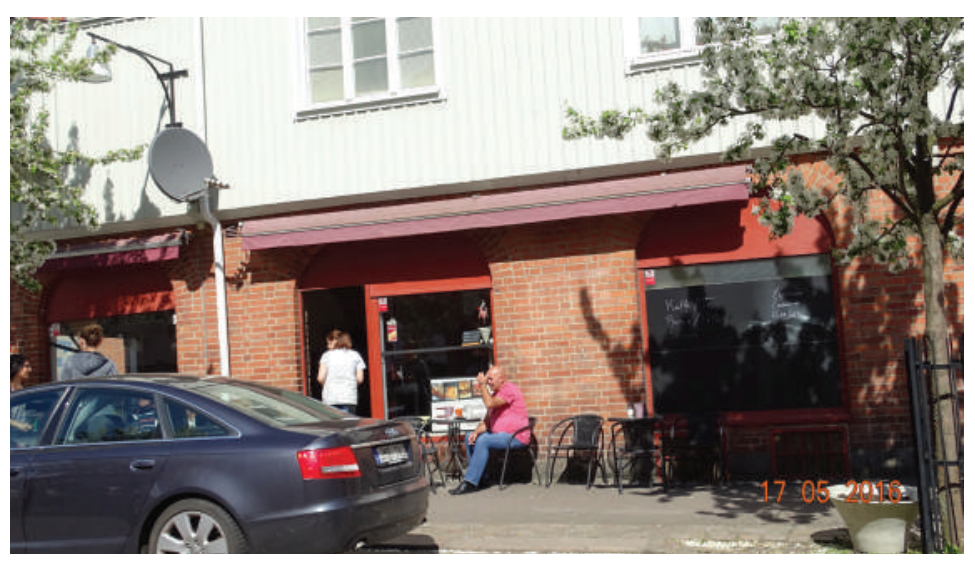

Figure 6: Storefront in Gamlestaden with 'old school' signage 
areas, although this is done recurring to different registers in the two neighbourhoods. In what follows we will give examples of these uses in the two neighbourhoods.

The Palestinian restaurant in Olivedal, shown in figure 7 , is named 'Silvis' after the former owner's wife and the present owner's mother ${ }^{2}$ - a female name written in an Arabic 'mimicry' font (Sutherland 2015) which forms part of the restaurant's logo, as if the name rose from the oil lamp. The name Silvis also appears on the four sunshades to the left of the entrance, but here it is written with Arabic calligraphy in al-Tughra'i style, originally developed under the Ottoman Sultans in the 13th century, but today most often used in religious contexts. The calligraphy style signals both worldly and religious authority, but is difficult to read, even for native speakers of Arabic, because of the writing direction (from lower right to upper left) and the position of the individual Arabic letters (Gibb 1986: 595-98). The use of Arabic calligraphy and the logo with the transliterated name features a minimalist design and makes the signage distinction-making. Using this particular al-Tughra'i style as well as gold-colored letters on the logo and the sunshades also reflects scalar work and suggests an increased symbolic value of Arabic within this setting.

The menu at the right hand side of the entry contains many Arabic words written in Latin letters. All dishes have Arabic names, and for each one a short Swedish description presents the ingredients for Swedish customers. Unlike the calligraphy, which indexes classical Arabic and thus represents the high variety of the diglossic Arabic language, the transliterated Arabic words on the menu are all derived from Palestinian colloquial, a low variety of Arabic which does not enjoy the same linguistic and religious prestige as classic Arabic (Ferguson 1959; Badawi 1973; Versteegh 2014). The use of the two different varieties in the same context, even in the same menu, sends mixed signals about the status of the restaurant, but since neither the calligraphy nor the Palestinian colloquial seem to have

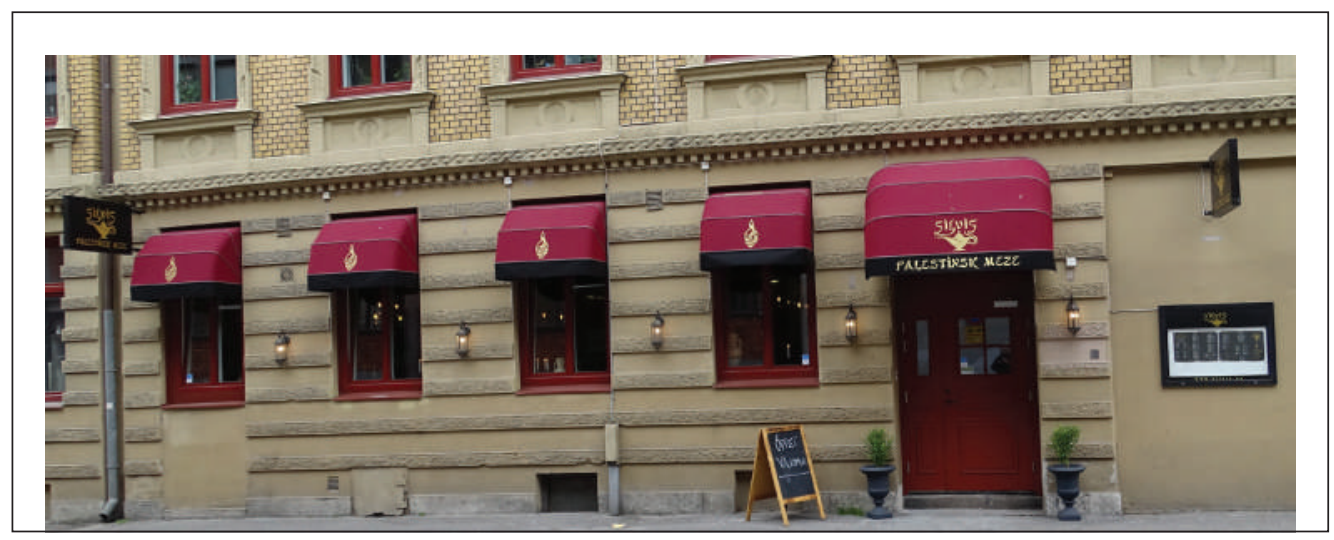

Figure 7: Restaurant Silvis in Olivedal

2 Silvis teaser, http://silvis.nu/index.html, 0:17, visited November 32017. 


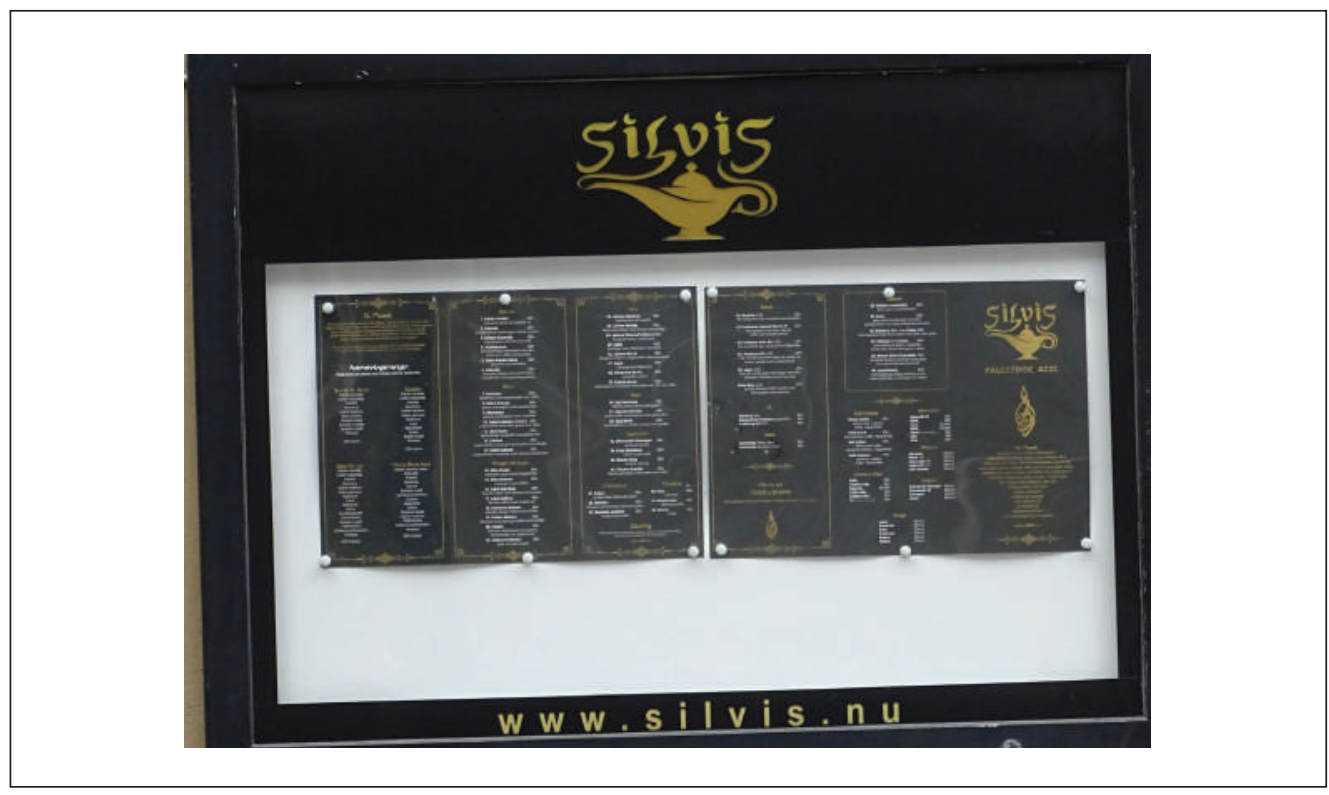

Figure 8: The menu at Silvis

any genuine communicative function in this context, the visual language usage presumably aims to signal cultural authenticity to customers who do not understand Arabic. Thus, the use of Arabic appears to be a linguistic fetish, in which 'form and symbolic meaning take precedence over content or utility' (Kelly-Holmes 2014: 139). Using a textsparse storefront based on calligraphy combined with the two different registers of Arabic in its high- as well as its lowvariety forms creates a 'one-of-a-kind identity' that sets it apart from other restaurants in the area (Trinch and Snajdr 2017: 80) and contributes to an upscaling of the restaurant's value of attraction. Additionally, the artistic use of cultural artefacts in the logo, on the menu (two oil lamps on the right hand side of the menu and four candlesticks formed by the text of the set menus at the left hand side) and on the restaurant's website, whose address is given below the menu (historical photo from Palestine, pictures of oriental belly dancing, etc.) as well as the descriptions of traditional Palestinian cuisine and its health effects, also mentioned on the website, makes it clear that this restaurant seeks to create a coherent cultural 'semiofoodscape' (Järlehed and Moriarty, 2018).

In Gamlestaden storefronts including Arabic generally follow the principle of 'what-you-see-is-what-youget' with large typefaces, store names referring to types of business and products or what Trinch and Snajdr have termed 'old school' vernacular signs, frequently used in not-yet-gentrified areas (Trinch and Snajdr 2017: 70). Jenans Gatukök is a case in point: The fast food restaurant's large bilingual sign in yellow and blue (corresponding to the colors of the Swedish flag) states the restaurant's name in Swedish and Arabic followed by the food items offered by the restaurant: 'Falafel, kebab, chicken, 
hamburgers, etc.' in both languages. The two languages are separated by a circular label displaying the word Halal in Arabic and Latin scripts, indicating that the food sold in this restaurant follows Islamic guidelines. Contrary to the restaurant in Olivedal the Arabic typefaces used here are immediately readable, indicating that Arabic has a genuine communicative function. All other texts used by Jenans Gatukök appear in Swedish which serves as a lingua franca for the ethnically diversified residents of the area.

Like Silvis in Olivedal, Jenan is a personal name, which can be used for women as well as for men, but it also has a strong religious connotation, being the plural of the Arabic word janna (pl. Jinan/Jenan) - garden or paradise. In the context of this snack bar one would immediately interpret Jenan written in Latin letters as a personal name. However, the word used is not jenan but jana'in, another plural of janna, with the same meaning, paradise. This plural form cannot be taken as a personal name, only as paradise, and this reading is supported by two additional features: jana'in is made definite by the prefix al-, thus indexing a specific place, and a short a-vowel (in the form of an almost horizontal short line) is added on the top of the first consonant of jana'in - a feature indicating that the word belongs unequivocally to the high variety of Arabic. The Arabic name of the fast food restaurant is thus 'Food from (the) Paradise', and this is by no means a coincidence. The restaurant is located next to the Bellevue Mosque, one of Gothenburg's oldest and most well-known mosques. From the outside the mosque is anonymous without any Islamic symbols or decorations. The only exception is a sign at a backdoor stating in Arabic 'Women's entrance to the mosque', translated into Swedish as 'kvinnor ingång' (women entrance), and a small piece of tape on the mailbox with the mosque's official name 'Islamiska Sunni Center' (Islamic Sunni Center). 'Food from Paradise' shows how the mosque invests the physical space around it with religious meaning, which

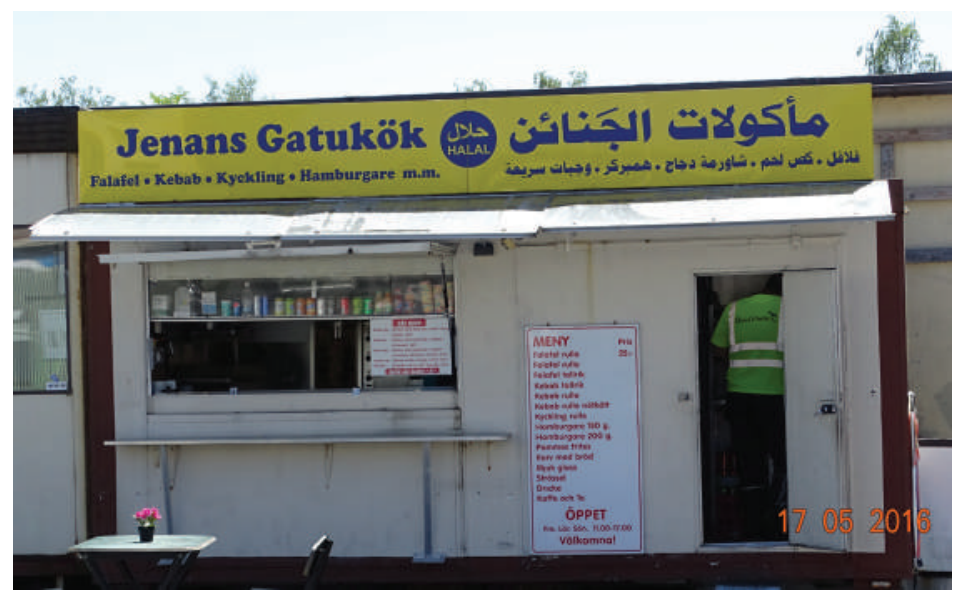

Figure 9: Jenans Gatukök in Gamlestaden 
is reflected in the visual language of the surrounding shops and businesses. This feature is also used by a nearby furniture store which has a large framed picture above the entrance with an open Koran and an Arabic text saying 'God (is) the Almighty and Muhammad (is) his messenger'. Commercial companies thus draw on the religious place-making of the otherwise anonymous mosque, but this is merely visible to those who are able to read Arabic. Moreover, in areas like Gamlestaden, with many different groups of Muslim immigrants, religiosity is not only indexed through neighbouring companies' use of names and religious expressions, but also by the fact that the register of classical Arabic, as it appears in e.g. the word al-jana'in, is the holy language of Islam and that using it in writing therefore signals 'high Islam’ (Moser 2012: 2921-22).

The southern part of Gamlestaden (Bellevue) is home to four mosques, and this attracts many visitors on Fridays from all over Gothenburg, who participate in the Friday prayer and then often go shopping or have lunch or coffee in the area afterwards. The mobility created by the mosques' pull-effect is utilized by restaurants and other companies to upscale their business, through what could be termed 'a proxy-approach'. The Castaletta restaurant, located in an industrial suburb $5 \mathrm{~km}$ north of Gamlestaden, illustrates how it works: The restaurant has put up a poster with a menu and contact information at a window in the immediate vicinity of two of the mosques. The poster promotes a special offer in Arabic where customers can 'Brunch and enjoy listening to (the famous Lebanese singer, author's remark) Feirouz' songs every Saturday and Sunday between 9 and 13' and 'enjoy a luxurious meal from Restaurant Castaletta as you like (it)'. The poster reminds Arabic-speaking Muslims who visit the neighbourhood on Fridays that Castaletta is worth a visit over the weekend. However, instead of using Swedish to present the dishes, as was the case with Jenans Gatukök, Castaletta displays photos of the food and write the Arabic names in Latin letters so as to allow customers who do not speak Arabic to read and pronounce the dishes as well as getting a visual impression of the food. This 'proxy-approach' of using posters, stickers, and other cheap advertising media used by companies located outside the neighbourhood is frequently used by such diverse businesses as transport and relocation companies, translators, and other smaller companies which try to exploit the horizontal mobility of mosque-goers as well as the communicative effects of the Arabic language for their own scalar work..

In Gamlestaden Arabic is thus not used as a fetish, but has a communicative and referential function, either as a religious register to upscale local businesses through the use of religious terminology or the high-variety of classical Arabic, or by using the pulleffect of the religious institutions for commercial ends. Furthermore, though the registers used by Silvis and Jenan's Gatukök differ in the sense that the former indexes non-native speakers of Arabic while the latter indexes religiously devoted Muslims, both registers are prestigious and highly valued in their local context. They are therefore likely to be used as aspirational interaction in the two different neighbourhoods, thus echoing distinction-making and up-scalar work. Castaletta, on the other hand, uses a gastronomic register which primarily indexes Arabic-speaking customers, but due to the extensive use of pictures on the poster, non-Arab Muslims 


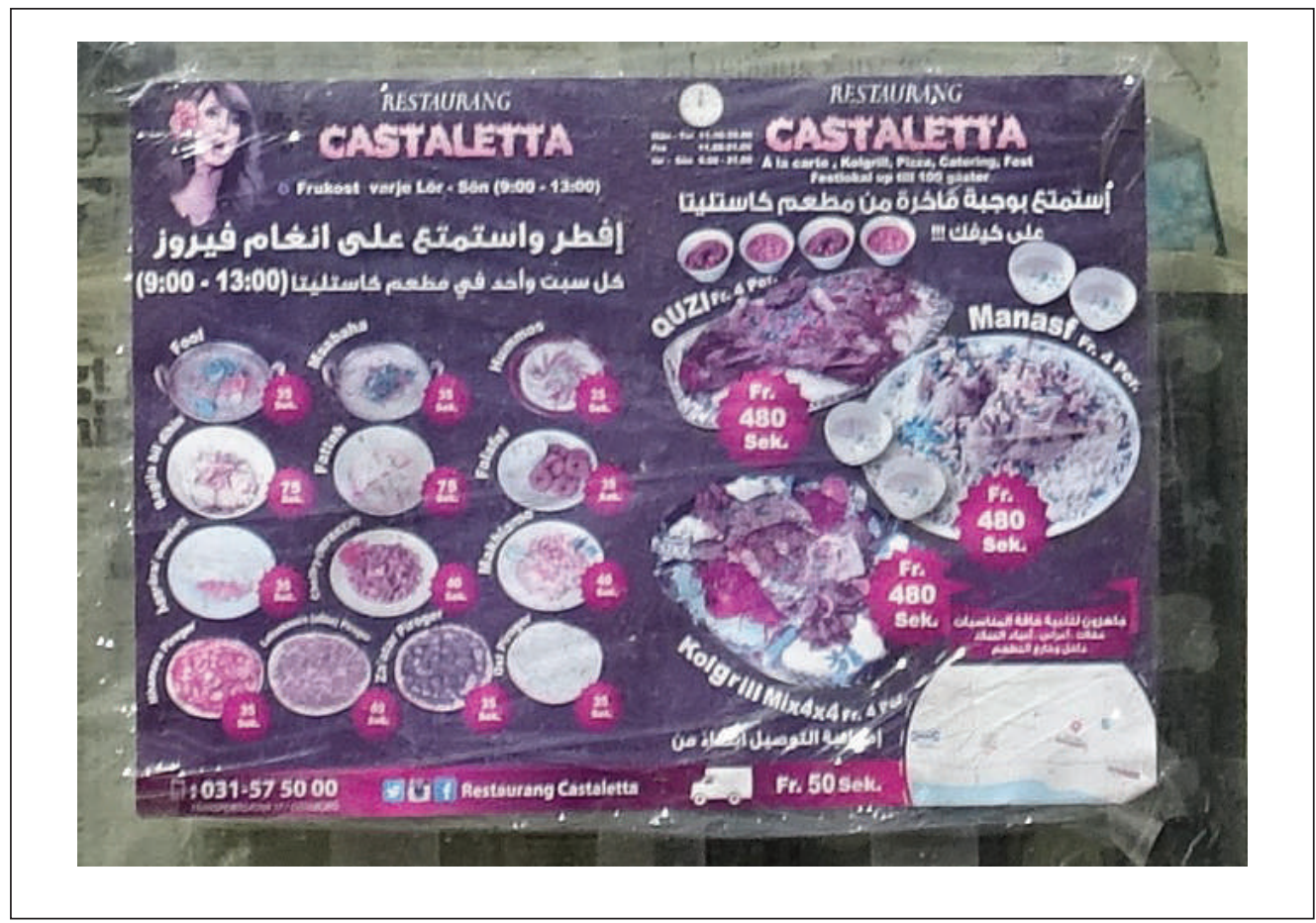

Figure 10: Castaletta's poster in Gamlestaden

can comprehend the register, resonating Old school vernacular signage.

\section{FOOD TRUCKS AND REGISTERS AS MOBILE GENTRIFICATION RESOURCES}

In this last section, we will focus on the use and function of gastronomic registers and food trucks within gentrification processes. In Gothenburg, these used to be rather simple mobile food carts that were serving generic and cheap fast food, but they are now rapidly replaced by chic and designed cars that offer more exclusive and gourmet food. We argue that both are at the same time gentrified and serving as tools for the gentrification of particular neighbourhoods. Figure 11 provides an example of a traditional food cart in Gamlestaden (left) and a distinction-making food truck in the Olivedal neighbourhood (right).

The picture of the simple food cart in Gamlestaden shows a number of modern Swedish words or loanwords, such as the Arabic falafel and kebab and the English burger. Although the Swedish Academy's Dictionary (SAOL) only lists the simple forms (kebab entered in 1986, falafel in 2006) of these Arabic words, their social acceptance as part of the Swedish language is clearly reflected in common composite expressions such as kebabrulle ('kebab roll') and falafeltallik ('falafel roll plate'). ${ }^{3}$ These features of Arabic have in the last three decades become part of a new Swedish gastronomic register available to the general public; 
both working class and middle class people master it. Its establishment in Sweden is mainly due to immigration of Arabic-speaking people who first spread the names through their snack bars. Later, when the Swedes got familiar with these foodstuffs, a market emerged for a broader circulation of falafel via supermarkets, restaurants, and home cooking.

The same can be said of some Italian coffee terms: espresso and cappuccino were included in the SAOL in 1986 and caffe latte in 2006, and today they are used across class boundaries. However, after more than a decade of intense exposure in restaurants, on TV and lifestyle magazines, and weekend trips to Italy, a sector of the Swedish urban elite has now acquired skills enough to order a full dinner in 'Italian'. A new gastronomic linguistic register thus emerges which the urban elite uses for marking social class belonging and differentiated taste.
It is therefore not surprising that we find an entire menu in Italian exhibited on the street in Olivedal (figure 11, bottom right). When you enter this and other Italian restaurants and cafés in Olivedal and other central middle class areas in Gothenburg, you are often greeted by a Buongiorno ('Good day') or Prego ('Can I help you/Please') and then thanked with a Grazie ('Thanks'). The staff generally mixes such Italian expressions with Swedish, and many customers include some Italian words in their orderings. Similarly, some customers to Arabicspoken restaurants and food carts try pronouncing the dishes in Arabic and inserting Arabic expressions like shukran ('thanks') and habibi ('my friend'). However, this is rather done to signal positive attitudes to Arabic language and culture, and to counter the stigmatized image generally ascribed to Arabic in Gothenburg and many other European cities. Due to the low social value of

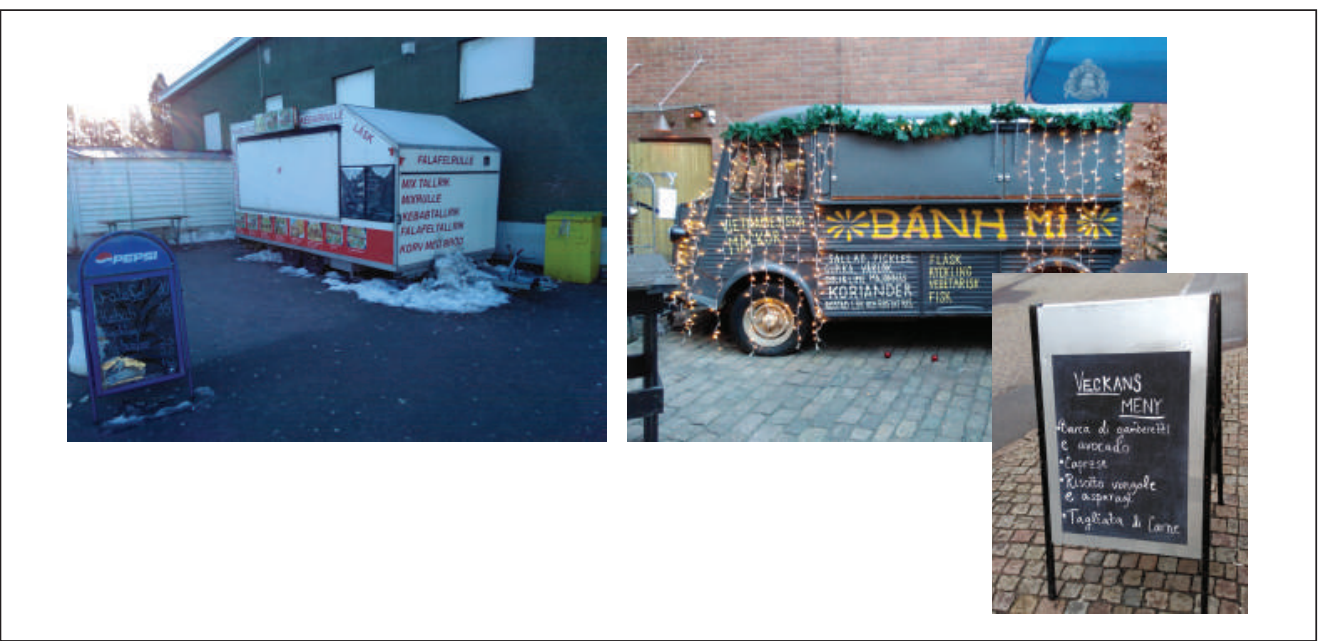

Figure 11: Foodtrucks and menus in Gamlestaden (left) and Olivedal (right)

3 Usage of these foreign food words in Sweden is documented since the 1970s (https://www.google.com/ url?q=https://svenska.se/so/?sok\%3Dkebab\%26pz\%3D4\&sa=D\&ust=1510304067787000\&usg=AFQ jCNH0B-KnF1eN2gUZ9zvbT5CL-F-pBQ ) but we sustain that it is only with their later incorporation into the Swedish Academy's Dictionary that we can see them as officially Swedish, and hence as part of popular gastronomic registers.

(C) Järlehed, Lykke Nielsen, Rosendal and CMDR. 2018 
Arabic in these places it is immobile and normally restricted to social interactions among Arabic speaking people, whereas the prestige associated with languages and cultures such as Italian and English makes them - or more precisely particular linguistic features that form part of a gastronomic register - highly mobile and useful resources for social up-scaling of people, places, and businesses.

While the popular gastronomic register of Swedish that includes Arabic names such as falafel and kebab indexes properties of the speakers' present situation and status, the elite gastronomic register of Swedish that includes basic politeness phrases and full menus in Italian, in addition to isolated names of exotic and faraway foodstuffs such as the Vietnamese bánh mì (see fig. 11), rather indexes a situation and status the speaker is aspiring to (Irvine 2001). Furthermore, the visual and graphic form given to expressions of these two gastronomic registers in commercial signage are closely related to the two patterns of pre- and post-gentrification in Brooklyn described by Trinch and Snajdr (2017): the many-wordy, vernacular and inclusive 'old school' signs, and the minimalist, exclusive and witty distinction-making storefronts.

The elite gastronomic register is not only mixing bits of high-status languages with Swedish, but also features minimalist design, celebration of vernacular lettering and foreign diacritics, and the rejection of overt signs of commercial dependency or sponsorship, such as the Pepsi logo on the blue sandwich board in Gamlestaden (fig. 11, bottom left).

In Olivedal we find a retro-chic Citroën food truck offering Vietnamese Bánh Mis, or sandwiches. As in Leeman and Modan's (2010) study of Chinatown in Washington DC, commodified language here co-occurs and interacts with features of the built environment. It is the form and symbolic value of words and expressions that count, not their content and connection to an on-site living language community. The Vietnamese words Bhán mì on the Olivedal foodtruck is in Kelly Holmes' (2014) words, a 'linguistic fetish' that contributes to the ongoing socioeconomic up-scaling of the neighbourhood.

The Vietnamese food truck is not just any food truck; it is part of one of last years' more spectacular restaurant investments in Gothenburg. The company Avenyfamiljen ('The Avenue Family') is one of the city's most powerful players in the restaurant scene. In 2013 they purchased the buildings of the old auction house on $3 e$ Langgatan and within a few months in 2014 they opened three restaurants, one food truck, a wine bar, a bakery, and a 'cultural arena'. They wanted to create a cosmopolitan air to the neighbourhood and thus chose a mix of foreign kitchens and names: the Mexican TacosETequila, the Italian Taverna Averna, the Vietnamese Bánh Mì, the French Levantine, and the 'international Chinese restaurant' Made in China (figure 12).

As Krase and Shortell (2011: 372) say, those with power 'differentiate' the urban space through 'appropriation and domination'. With their choice of highly designed and ethnically themed kitchens, Avenyfamiljen appropriated a variety of linguistic, visual, and material resources from other cultures and places to attract financially strong consumers and consolidate their domination of the city's restaurants, and its residents' taste preferences. Each restaurant displays distinction-making signage (e.g. the minimalist and playful meta-commentary produced by the name Made in China) but also features commissioned street 
art and graffiti, such as the adaptation of communist Chinese iconography to celebrate Gothenburg's emblematic but lost shipyards (mural inside Made in China). The 'visual symbolic capital' (Gendelman and Aiello 2010: 258) of street art is clearly illustrated by the fact that the owners chose to pose in front of it in local media coverage. ${ }^{4}$

In addition to the above, Avenyfamiljen created Auktionshusets Kulturarena, a space for 'cultural events' which so far mainly have consisted in stand-up and fashion shows, weddings, corporate events, and conferences (https://www.auktionsverketkulturarena. $\mathrm{se} /$ ). That is, what is offered here is a kind of commercialized and sanitized culture directed to the same audience as the one attracted by the thematised restaurants at the street level of the building.

Altogether, Avenyfamiljen's establishment on $3 e$ Långgatan illustrates the intermingling of public and private initiatives common to gentrification processes (the investor needed permissions of the local civil servants). In particular, this investment contributes to what Leeman and Modan (2009: 338) describe as the 'blurring of the boundaries between culture and consumption': 'Culture is used both to frame public space and to legitimate the appropriation of that space by private and commercial interests (Zukin 1998). As cities and themed environments become sites of 'shopertainment' (Hannigan 1998), consumption becomes culture, and culture becomes consumption.

What we see in Gothenburg is part of a worldwide process of up-scaling of street-food (e.g. Hanser and Hyde 2014; Martin 2014; Newman and Burnett 2013). The process is reflected in the linguistic landscape in several ways: the Swedish terms gatukök and matvagn are replaced by the English food truck; the city of Gothenburg offers several street food markets and festivals in different parts of town; and the city's convention bureau includes a detailed verbal and visual description of the city's food trucks on its webpage (http://www. goteborg.com/en/foodtrucks/). The city council is thus deeply involved in these up-scaling processes. Until a renovation

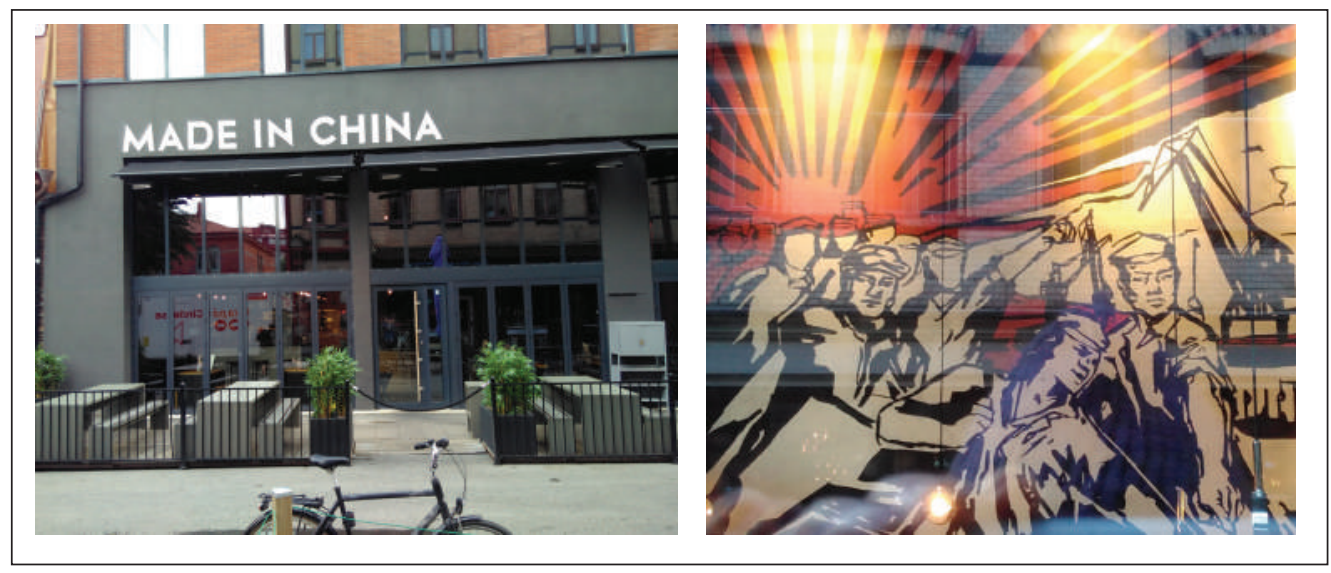

Figure 12: Storefront and mural in Made in China, Olivedal

4 Similarly, Papen $(2015,20)$ has shown how street-art in Berlin 'albeit illegal, is not only tolerated but seen as attractive and used for the purposes of place-making - advertising the neighbourhood to entice new residents, visitors, tourists and investors'. 
of the central market hall (Saluhallen) began in 2010, simple, white, food carts like the ones found in Gamlestaden were standing on Kungstorget or the 'Royal Square' in central Gothenburg. They offered falafel, hamburgers, langos and similar cheap generic 'ethnic' foods, normally listed with unfancy writing on simple white boards. When the renovation began the municipality cancelled all the licences. When the hall was reopened, new permits were distributed, but only to food trucks with an aesthetically pleasing design and the 'correct' offer of thematised street-food. At the Royal Square and in the nearby square by Magasinsgatan there are now about 10-15 food trucks, several of them specialized in 'ethnic' or 'exotic' food - i.e. food that is deviating from the normative understanding of 'Swedish' food, just as the one on 3e Lainggatan in Olivedal (fig.11, right).

The described process contributed and still contributes to a horizontal redistribution with gourmet food trucks occupying the economically important sites and the traditional or 'old school' food carts and snack bars being displaced to economically and visually peripheral parts of town. It is also a vertical process which resonates and reinforces the unequal socioeconomic valuing of different kinds of street food.

\section{CONGLUSION}

This paper was concerned with the interaction of language, food, and gentrification. Examining traces of social and economic mobility in the visual and material surface of two Gothenburg neighbourhoods, we saw how the horizontal distribution of separate resources such as particular languages, gastronomic register forms, and foodtrucks is conditioned by a vertical and uneven distribution of social and economic power. People reproduce this hierarchy and orient after it as they make their daily choices of consumption (taking away a caffe latte or a bhán mi) and long term investments (buying a flat or opening up a restaurant).

We conclude that the (im)mobility of particular semiotic resources is largely determined by the socioeconomic value that they are ascribed in particular TimeSpaces. By extension, this value ascription is conditioning the (im) mobility of the people who are using these resources, be they specific languages, gastronomic registers or foodtrucks. Drawing on and expanding Irvine's (2001) account of register, we put forward the notion of gastronomic register to deal with socioeconomic scalar work within gentrification. Gastronomic registers and individual languages are part of systems of distinction. Within ever more competitive and trend-sensitive cities, the production of distinction emerges as key for socioeconomic growth and success. We can thus see how particular semiotic resources such as individual languages, gastronomic registers, fancy foodtrucks, and street art are deployed in gentrification processes to attract the attention on new investors, consumers, inhabitants, and visitors, and to thematize and brand businesses and places as unique and exclusive. Yet, although this study analyzed the city of Gothenburg, globalization has contributed to the production and dissemination of a rather generic and standardized repertoire of gentrifying resources which are used in similar ways in cities all over the world (see e.g. Hanser and Hyde 2014 and Irvin 2017 on foodtrucks, Kelly-Holmes 2014 and Girardelli 2004 on individual languages such as English and Italian, and Papen 2015 on street art). 
We further observed how the distinction-making and upscaling was achieved both in written and spoken communication as people deploy little bits of Italian or Arabic when engaging in aspirational social interactions in the neighbourhoods' cafés and restaurants. In Gamlestaden we could also see how religious institutions such as mosques have an important pull-effect on people, language, and capital which leaves traces and reshapes the linguistic landscape. However, Arabic and Islam interacts with specific places in particular ways (like all languages and faiths). In Olivedal where there is no mosque and no (large) Muslim community, the Arabic language and visual markers of Middle Eastern culture rather serve as a kind of visual fetish, attracting visitors to the Palestinian restaurant.

Finally, when analysing gentrification we should be aware that it is intrinsically mobile: gentrification is a land-consuming practice driven by capital. When a piece of land such as a neighbourhood is becoming gentrified, the margin for profit decreases and the investors and capital move on, to new land. Parallel to this, less affluent people and businesses are forced to move from the neighbourhoods being gentrified, and they take the linguistic and material resources needed for their businesses with them. As a consequence, the kind of 'old school' signage described by Trinch and Snajdr (2017) and the traditional food carts do not disappear from town, but are displaced to marginalized and poorer areas, such as the Bellevue district of Gamlestaden. Gentrification hence involves both centrifugal and centripetal forces since it attracts certain social groups and linguistic practices but repels others.

\section{REFERENCES}

Badawi, El-Said. 1973. Mustawayāt Al'Arabìyah Al-Mu 'āṣirah F̄̄ Mișr. Cairo: Dār al-Ma'ārif.

Berg, Per Olof, and Guje Sevón. 2014. Foodbranding places - A sensory perspective. Place Branding and Public Diplomacy 10 (4): 289-304. https://doi.org/10.1057/ pb.2014.29.

Blackledge, Adrian, Angela Creese and Jaspreet Kaur Takhi. 2014. Voice, register and social position. Special Issue: Researching multilingualism and superdiversity: Grassroots actions and responsibilities. Multilingua. 33(5-6): 485-504.

Blommaert, Jan. 2010. The Sociolinguistics of Globalization. Cambridge Approaches to Language Contact. Cambridge: Cambridge University Press.

— . 2013. Ethnography, Superdiversity and Linguistic Landscapes. Bristol: Multilingual Matters.

Blommaert, Jan, and Ben Rampton. 2011. Language and superdiversity. DIVERSITIES 13 (2): 1-22.

Bourdieu, Pierre. 1984. Distinction: A Social Critique of the Judgement of Taste. New ed. London: Routledge.

Carr, E. Summerson, and Michael Lempert. 2016. Scale. University of California Press.

City of Gothenburg. 2018. Gothenburg celebrates 400 years. Official website: <http://www.goteborg2021.com/ english/>

Coupland, Nikolas. 2016. Five Ms for sociolinguistic change. In Nikolas Coupland (ed.). Sociolinguistics: Theoretical Debates. Cambridge: Cambridge University Press. 433-454.

Del Percio A., Flubacher M. \& Duchêne A. 2017. Language and Political Economy, In Garcia O., Flores N., Spotti M. (eds.). The Oxford Handbook of Language and Society. Oxford: Oxford University Press. $55-75$.

DeSena, Judith N. 2012. Gentrification in everyday life in Brooklyn. In Judith $\mathrm{N}$ 
DeSena and Timothy Shortell (eds.). The World in Brooklyn: Gentrification, Immigration, and Ethnic Politics in a Global City. Plymouth: Lexington Books. 65-88.

Edensor, Tim. 2010. Walking in rhythms: Place, regulation, style and the flow of experience. Visual Studies 25 (1): 69-79.

Ferguson, Charles A. 1959. Diglossia. WORD 15 (2): 325-340.

Gal, Susan. 2018. Registers in Circulation: The Social Organization of Interdiscursivity. Signs and Society 6(1): 1-24.

Gendelman, Irina, and Giorgia Aiello. 2010. Faces of places: Façades as global communication in post-eastern bloc urban renewal. In Adam Jaworski and Crispin Thurlow (eds.). Semiotic Landscapes: Language, Image, Space. London/Oxford: Bloomsbury Publishing. 256-273.

Gibb, Hamilton Alexander Rosskeen. 1986. The Encyclopaedia of Islam, New Ed., 13 . Leiden, Netherlands: E.J. Brill.

Giolla Chríost, Mac. 2007. Language and the City. Language and Globalization. Basingstoke: Palgrave Macmillan UK.

Girardelli, D. 2004. Commodified identities: The myth of Italian food in the United States. Journal of Communication Inquiry 28 (4): 307-324.

Hanser, A., and Z. Hyde. 2014. Foodies remaking cities. Contexts 13 (3): 44-49.

Heller, Monica. 2007. Bilingualism as ideology and practice. In Monica Heller (ed.). Bilingualism: A Social Approach. Basingstoke: Palgrave Advances in Linguistics. Palgrave Macmillan UK. $1-22$.

Holgersson, Helena. 2014. Post-political narratives and emotions: Dealing with discursive displacement in everyday life. In Hannah Jones and Emma Jackson (eds.). Stories of Cosmopolitan Belonging: Emotion and Location. London: Routledge. 115-126.

Holgersson, Helena, and Catharina Thörn (eds.). 2014. Gentrifiering. 1. uppl. Lund: Studentlitteratur.

Hultgren, Åsa. 2012. Långgatorna i Masthugget - karaktärisering och analys av stadsmiljö.
Gothenburg: City of Gothenburg,

Göteborgs stadsbyggnadskontor.

$<$ http://www5.goteborg.se/prod/

fastighetskontoret/etjanst/planobygg.

nsf/vyFiler/Linn\%C3\%A9staden\%20

-\%20Kvarteret\%20Barken-

Plan\%20-\%20samr\%C3\%A5d-

Karakt\%C3\%A4risering\%20och\%20 analys\%20av\%20stadsmilj\%C3\%B6/\$File/ L\%C3\%A5nggatorna\%20

i\%20Masthugget $\% 20-\% 20$

karakt\%C3\%A4risering\%20och\%20 analys\%20av\%20stadsmilj\%C3\%B6. pdf?OpenElement>

Hutton, C. M. 2011. Vernacular spaces and 'non-places' : Dynamics of the Hong Kong linguistic landscape. In Messling, M (ed.). Stadt Und Urbanität: The New Metropolis - Die Neue Metropole. Berlin: Kulturtverlag Kadmos.162-184.

Irvin, Cate. 2017. Constructing hybridized authenticities in the gourmet food truck scene. Symbolic Interaction 40 (1): 43-62.

Irvine, Judith T. 2001. 'Style' as distinctiveness: The culture and ideology of linguistic differentiation. In Penelope Eckert and John R. Rickford (eds.). Style and Sociolinguistic Variation. Cambridge: Cambridge University Press. 21-43.

Jaworski, Adam. Forthcoming 2018. The art of silence in upmarket spaces of commerce. In Martin Pütz and Neele Mundt (eds.). Expanding the Linguistic Landscape: Multilingualism, Language Policy and the Use of Space as a Semiotic Resource. Bristol: Multilingual Matters.

Jaworski, Adam, and Crispin Thurlow, eds. 2010. Semiotic Landscapes: Language, Image, Space. Advances in Sociolinguistics. London: Continuum.

Järlehed, Johan, and Máiréad Moriarty. 2018 , in press. Under review. Culture and class in a glass: scaling the semiofoodscape. Language \& Communication. Pp. 1-13. https://doi. org/10.1016/j.langcom.2018.05.003

Lou, Jackie Jia. 2016. The linguistic landscape of Chinatown: A sociolinguistic ethnography. Clevedon: Multilingual Matters. 
Jørgensen, J. Normann. 2008. Polylingual languaging around and among children and adolescents. International Journal of Multilingualism 5 (3): 161-176.

Jörnmark, Jan, Joakim Forsemalm, and Karl Palmås. 2016. Göteborg - mellan segregation och kreativitet. PLACE: Tangent förlag.

Kelly-Holmes, Helen. 2014. Linguistic fetish: The sociolinguistics of visual multilingualism. Visual Communication 4: 135-151.

Krase, J., and T. Shortell. 2011. On the spatial semiotics of vernacular landscapes in global cities. Visual Communication 10 (3): 367-400.

Lanza, Elizabeth, and Hirut Woldemariam. 2014. Indexing modernity: English and branding in the linguistic landscape of Addis Ababa. International Journal of Bilingualism 18 (5): 491-506.

Leeman, Jennifer, and Gabriella Modan. 2009. Commodified language in Chinatown: A contextualized approach to linguistic landscape. Journal of Sociolinguistics 13 (3): 332-362.

-. 2010. Selling the city: Language, ethnicity and commodified space. In Elana Shohamy, Eliezer Ben-Rafael, and Monica Barni (eds.). Linguistic Landscape in the City. Bristol: Multilingual Matters. 182-198.

Lin Pan. 2010. Dissecting multilingual Beijing: The space and scale of vernacular globalization. Visual Communication 9 (1): 67-90.

Lou, Jackie Jia. 2016. The linguistic landscape of Chinatown: A sociolinguistic ethnography. Multilingual Matters.

Loukaitou-Sideris, Anastasia. 2002. Regeneration of urban commercial strips: Ethnicity and space in three Los Angeles neighborhoods. Journal of Architectural and Planning Research 19 (4): 334-50.

Lyons, Kate, and Itxaso Rodríguez-Ordóñez. 2015. Public legacies: Spanish-English (in) authenticity in the linguistic landscape of Pilsen, Chicago. University of Pennsylvania Working Papers in Linguistics 21 (2), article 14.
Martin, Nina. 2014. Food Fight! Immigrant street vendors, gourmet food trucks and the differential valuation of creative producers in Chicago. International Journal of Urban and Regional Research 38 (5): 1867-1883.

Moser, Sarah. 2012. Circulating visions of 'High Islam': The adoption of fantasy Middle Eastern architecture in constructing Malaysian national identity. Urban Studies 49 (13):2913-35.

Newman, Lenore Lauri, and Katherine Burnett. 2013. Street food and vibrant urban spaces: Lessons from Portland, Oregon. Local Environment 18 (2): 233-248.

Papen, Uta. 2012. Commercial discourses, gentrification and citizens' protest: The linguistic landscape of Prenzlauer Berg, Berlin. Journal of Sociolinguistics 16 (1): 56-80.

- 2015. Signs in cities: The discursive production and commodification of urban spaces. Sociolinguistic Studies 9 (1): $1-26$.

Piller, Ingrid. 2001. Identity constructions in multilingual advertising. Language in Society 30 (2): 153-186.

Roe, Maggie, Ingrid Sarlöv Herlin, and Suzanne Speak. 2016. Identity, food and landscape character in the urban context. Landscape Research 41 (7): 757-772.

Shaw, Kate. 2008. Gentrification: What it is, why it is, and what can be done about it. Geography Compass 2 (5): 1697-1728.

Shortell, Timothy. 2016. Everyday Globalization: A Spatial Semiotics of Immigrant Neighborhoods in Brooklyn and Paris. Routledge Studies in Human Geography 60. New York: Routledge.

Stroud, Christopher, and Sibonile Mpendukana. 2009. Towards a material ethnography of linguistic landscape: Multilingualism, mobility and space in a South African township, Journal of Sociolinguistics 13/3, 2009: 363-386.

Sutherland, Paul. 2015. Writing system mimicry in the linguistic landscape. SOAS Working Papers in Linguistics 17: 147-167. 
Thurlow, Crispin, and Adam Jaworski. 2003. Communicating a global reach: Inflight magazines as a globalizing genre in tourism. Journal of Sociolinguistics 7 (4): 579-606.

Trinch, Shonna, and Edward Snajdr. 2017. What the signs say: Gentrification and the disappearance of capitalism without distinction in Brooklyn. Journal of Sociolinguistics 21 (1): 64-89.
Vandenbroucke, Mieke. 2016. Socioeconomic stratification of English in globalized landscapes: A market-oriented perspective. Journal of Sociolinguistics 20 (1): 86-108.

Versteegh, Kees. 2014. The Arabic Language. Edinburgh University Press.

Zukin, Sharon. 2010. Naked City: The Death and Life of Authentic Urban Places. Oxford and New York: Oxford University Press. 